\title{
Evaluation of the TIG-MIG/MAG welding process in direct polarity
}

\author{
Gabriella Cristina da Silva Costa ${ }^{1} \cdot$ André Alves de Resende $^{1}$
}

Received: 23 October 2019 / Accepted: 3 January 2020 / Published online: 8 January 2020

(c) Springer Nature Switzerland AG 2020

\begin{abstract}
The associations of tungsten inert gas (TIG) and metal inert gas/metal active gas (MIG/MAG) welding process intends to take advantage of the higher productivity of the MIG/MAG process with the greater heat control imposed by the TIG process. In this context, the present study aims to evaluate the effects of the TIG-MIG/MAG process with both electrodes in direct (negative) polarity in weld bead geometry. A pioneering research on TIG-MIG/MAG process was carried out for the purpose of writing this article. Therefore, weld beads were made by the conventional MIG/MAG process and by the TIG-MIG/MAG process. Two input parameters, the MIG/MAG polarity and the TIG current, were evaluated. The output responses such as bead width, reinforcement, penetration, melted area, and convexity angles were evaluated. Macrographs were performed to measure the geometrical parameters of the weld bead. The results of these measurements were evaluated by a variance analysis. The results show that the polarity variation has an influence to modify the weld bead geometry in a TIG-MIG/MAG welding process. It was also noticed that the insertion of TIG current caused the tendency to greater wettability, penetration, melted area, width, and smaller reinforcements of weld beads.
\end{abstract}

Keywords Hybrid process · MIG/MAG · TIG · Direct polarity · Weld bead geometry

\section{Introduction}

The search for improvements in productive capacity, resource utilization, product quality, reduction of production costs, among others is encouraging the research progress related to the improvement of welding processes. The hybrid welding is described by El Rayes et al. [1] as the junction of two welding processes resulting in a new one with unique characteristics. According to the authors, the expectation to increase the areas of application and capabilities of associated processes present a significant advantage. A research related to the combination of two or more welding processes was performed in the 1970s [2]. This research aims to create processes that lead to results that could not be reached individually. Thus, they enable the emergence of new techniques and procedures with potential to improve aspects related to productivity, quality, and process operation.
The tungsten inert gas process (TIG) and metal inert gas/metal active gas (MIG/MAG) are widely used in the industrial sector. They provide high production of various materials and welds with low operating costs. The combination of both processes results in the TIG-MIG/MAG welding process. This combination intends to take advantage of the particularities of each one to produce improvements in weld quality. Figure 1 schematically illustrates the process. The authors [3-6] present studies in TIG-MIG/MAG process. The results show that the TIG arc in a stable process has influence to stabilize the MIG/MAG arc and preheat the base metal. Thus, an increase of spreading and wetting of the molten metal was noticed [5]. This preheating capability of the base material generates a difference in the geometry of the weld beads according to the parameters used in the process [6].

An appropriated selection of welding parameters is a fundamental aspect when a good quality of the weld

André Alves de Resende, aaresende@gmail.com | ${ }^{1}$ Laboratory of Mechanical Manufacturing, Engineering School, Federal University of Catalão - UFCAT, Catalão, Brazil. 


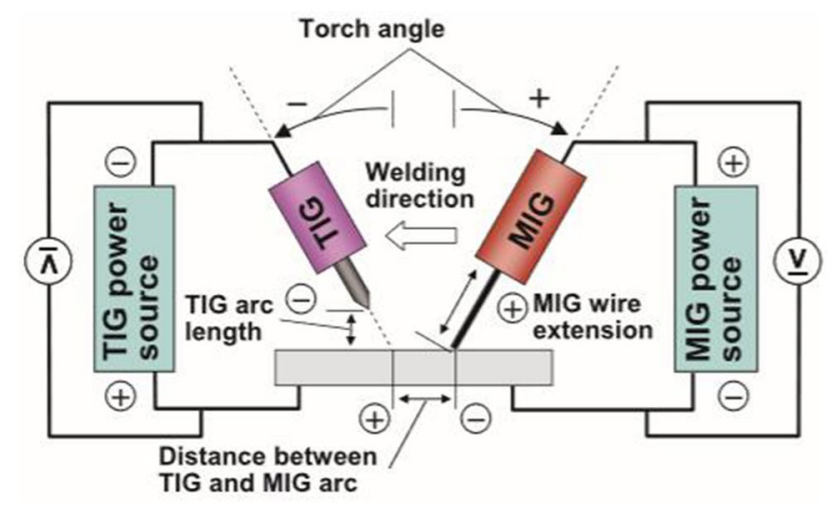

Fig. 1 Schematic model TIG-MIG/MAG welding [7]

bead is aimed at. The studies found in the literature on TIG-MIG/MAG involve various parameters and variables aiming at advances in areas such as welding speed [5, 8], improvement in appearance and geometry of the weld beads $[4,6,9]$, heat distribution in the joint, and so on $[10,11]$. It is noteworthy that all studies use the same configuration seen in Fig. 1. Thus, there are shortcomings related to parameters such as inverse polarity (electrode negative) in the MIG/MAG process that, among other things, is able to change the performance of the process.

For the MIG/MAG welding process, Lancaster [12] and Talkington [13] showed that welding in negative polarity (also known as direct polarity) allows a higher electrode fusion rate for the same welding current. However, the resulting weld bead has low penetration compared to positive polarity (also known as inverse polarity). This is because there is less heat input onto the plate in direct polarity. Another aspect is the convex shape of the weld bead, which can make its use unfeasible. For the same welding current, [14] achieved in approximately $60 \%$ higher wire feed speeds at direct polarity. In this context, the TIG-MIG/MAG welding process in this configuration intends to combine the high melting capacity of the MIG/MAG electrode in direct polarity with the additional heat input onto the plate by the TIG process.

The knowledge of all the aspects and variants of a process is of great importance. The control of all parameters involved support to achieve optimum productivity and efficiency. This work aims to evaluate the TIG-MIG/ MAG hybrid welding process in direct polarity (negative for both torches).

The reduction in the weld bead convexity effect is expected when compared to the conventional MIG/ MAG process. The effect of the TIG arc associated with the MIG/MAG arc on the other weld bead parameters will also be evaluated.

\section{Experimental procedure}

To perform the experiments, it was used a welding bench dedicated to the TIG-MIG/MAG process. A multiprocess power source model DIGIPlus A7 was used for MIG/MAG part of the process. An inverter power source model LHN 220i PLUS was used for TIG part of the process. A specific support was applied to integrate MIG/MAG and TIG standard torches. A welding positioner model TARTILOPE V2 was used to move the torches.

A set of six experiments was done by depositing a weld bead on plate. The material used was SAE 1020 carbon plates with dimensions of $200 \times 50.8 \times 6.35 \mathrm{~mm}$. It was defined a factorial design consisting of two factors, the parameters of control, that is, the polarity of MIG/MAG circuit (inverse and direct) and the TIG current intensity $(0,50$, and $150 \mathrm{~A})$. The tests without current in TIG circuit ( $0 \mathrm{~A})$ correspond to the conventional MIG/ MAG process (tests 1 and 2). Table 1 shows operating parameters kept constant in all experiments.

The MIG/MAG current was set at $250 \mathrm{~A}$. Under these conditions, the characteristics of the electrical signals and sound are typical of spray metal transfer. The voltage levels and power and welding speed were adjusted for each of the polarities, ensuring a constant relationship between welding speed and wire feed speed. Table 2 shows the parameters of the MIG/MAG process resulting from the adjustment of both polarities.

The following response variables were evaluated: reinforcement, penetration, width, molten area in the base metal, and convexity angle of the weld beads. After experiments' performance, the specimens were cut and the cross sections were metallographically analyzed. The cross sections were prepared in a grinding machining model "Teclago PVV" with grits 120\#, 180\#, 220\#, 360\#, $400 \#$ and $600 \#$ in this sequence. Furthermore, the specimens were etched using Nital (10\%) to reveal their macrostructures. The pictures were taken with a digital USB microscope.

\section{Results and discussions}

Table 3 shows the cross sections of the samples marking their fused areas. Table 4 displays the images of the surfaces of the plates.

Table 3 shows the effect of the parameters on the geometry of the weld. It can be seen aspects related to wettability, penetration, and width of the strands according to the variables studied. Table 4 displays images of the surfaces of the plates. These results are similar to 
Table 1 Fixed operating parameters

\begin{tabular}{ll}
\hline Parameter & Quantification \\
\hline TIG electrode diameter & $2.4 \mathrm{~mm}$ \\
TIG electrode type & AWS A5.12-98-2-EWTH \\
TIG electrode point angle & $30^{\circ}$ \\
TIG shielding gas flow & $100 \% \mathrm{Ar} 10 \mathrm{I} / \mathrm{min}$ \\
TIG torch angle & $0^{\circ}$ \\
Distance between the TIG electrode and workpiece & $5 \mathrm{~mm}$ \\
TIG polarity & negative \\
MIG/MAG electrode wire type & AWS A5.18 ER70S-6 \\
MIG/MAG electrode wire diameter & $1.2 \mathrm{~mm}$ \\
Distance between the MIG/MAG contact tip to the plate (stick-out) & $20 \mathrm{~mm}$ \\
MIG/MAG shielding gas flow & $\mathrm{Ar}+8 \% \mathrm{CO}_{2}$ at $15 \mathrm{I} / \mathrm{min}$ \\
MIG/MAG angle torch & $-30^{\circ}$ \\
MIG/MAG current & $\mathrm{A} \approx 250$ \\
Distance between electrodes & $12 \mathrm{~mm}$
\end{tabular}

Table 2 Operational variables parameters

\begin{tabular}{lll}
\hline Parameters & Levels & \\
\hline MIG/MAG polarity & Inverse (electrode + ) & Direct (electrode -) \\
MIG/MAG voltage & $30.0 \mathrm{~V}$ & $32.4 \mathrm{~V}$ \\
MIG/MAG wire feed & $8 \mathrm{~m} / \mathrm{min}$ & $11 \mathrm{~m} / \mathrm{min}$ \\
$\quad$ speed & & \\
Welding speed & $80 \mathrm{~cm} / \mathrm{min}$ & $110 \mathrm{~cm} / \mathrm{min}$ \\
\hline
\end{tabular}

those reported by [15]. Due to the characteristics of the process, the weld beads made in direct MIG/MAG polarity have the following characteristics: high instability in their format strings with greater convexity and greater amount of spatter, especially for the current intensity of $50 \mathrm{~A}$. Table 5 shows the results of measurements of the cross sections of the experiments.

With these data, a variance analysis of was performed by listing the control parameters with the response parameters. A $95 \%$ degree of reliability was considered. $P$ value equal or less than 0.05 has significant influence on the output response. The results of the analysis of variance can be seen in Fig. 2.

Any of the variables employed had a significant influence on the reinforcement response. Both, penetration and melted areas, suffer significant influence of all the input parameters. The width and the convexity angle have only the effect of MIG/MAG polarity. In general aspects, the MIG/MAG polarity has more significance in the intensity parameters than TIG current. For a better analysis and understanding of the variable response behavior, the data related to its interactions were plotted in graphs.

Figure 3 shows the effect of these parameters on the width. It is observed that the insertion of the TIG arc in both polarities tends to increase the width of the weld beads. The TIG arc increases the area of the heated plate in the inverse polarity, and hence the wettability. Inverse polarity causes an increase in the bead width compared to direct polarity as mentioned in [15]. The increase of $100 \mathrm{~A}$ in TIG current generated small differences in weld
Table 3 Images of cross sections of the experiments

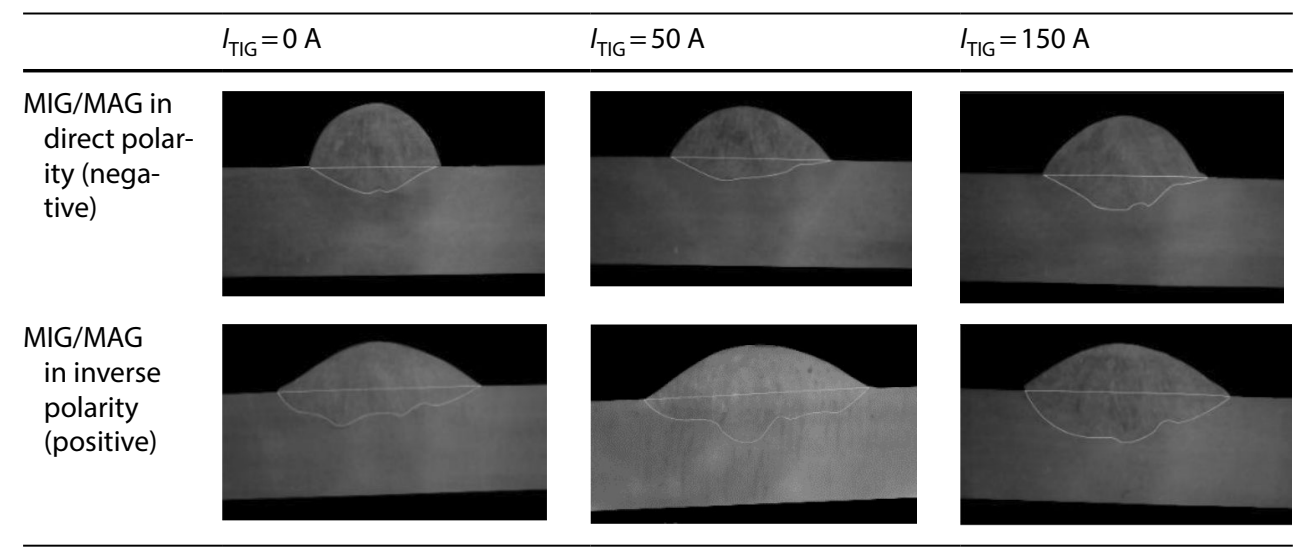

Plate thickness of $6.35 \mathrm{~mm}$ 
Table 4 Images of the samples surfaces

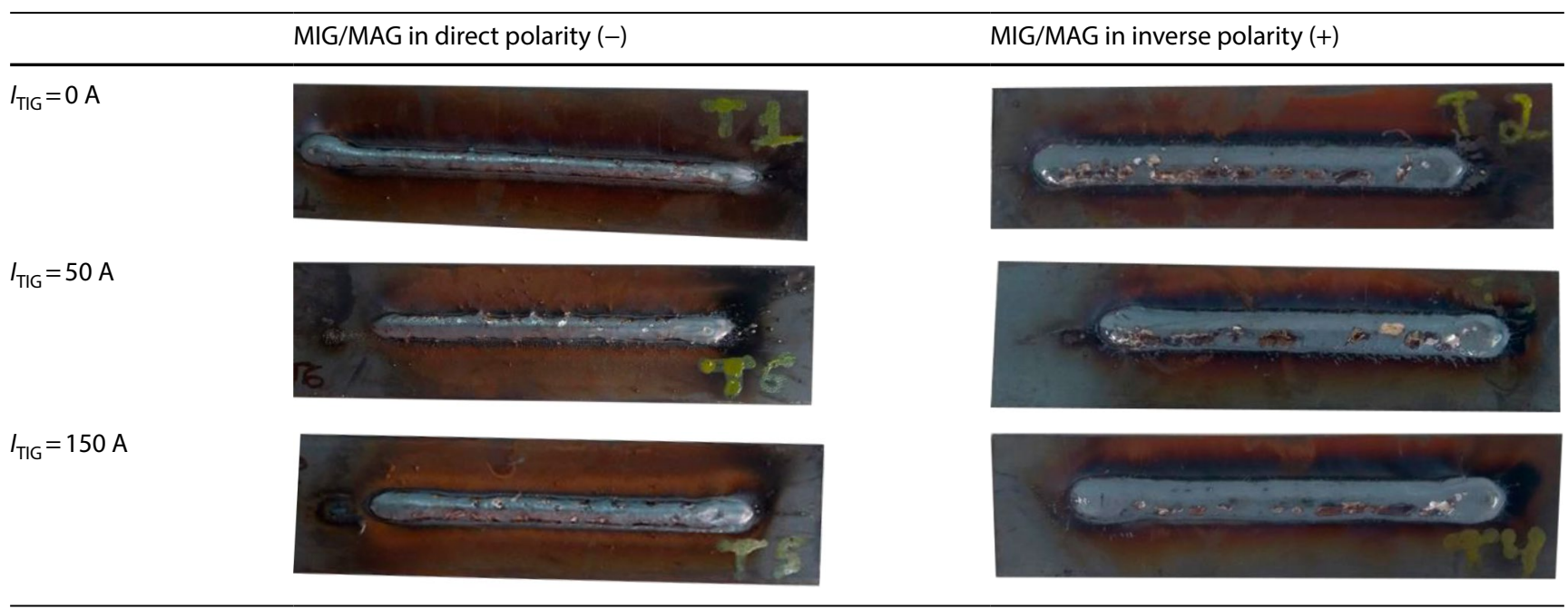

Table 5 Measured values of the geometric parameters

\begin{tabular}{llrlllll}
\hline Tests & MIG/MAG Polarity & $I_{\text {TIG }}(\mathrm{A})$ & $\begin{array}{l}\text { Reinforce- } \\
\text { ment }(\mathrm{mm})\end{array}$ & Width $(\mathrm{mm})$ & $\begin{array}{l}\text { Penetra- } \\
\text { tion }(\mathrm{mm})\end{array}$ & $\begin{array}{l}\text { Melted } \\
\text { area }\left(\mathrm{mm}^{2}\right)\end{array}$ & $\begin{array}{l}\text { Convexity } \\
\text { angle }\left({ }^{\circ}\right)\end{array}$ \\
\hline 2 & Inverse (+) & 0 & 2.90 & 12.50 & 2.15 & 16.75 & 37.0 \\
3 & & 50 & 2.92 & 13.58 & 1.89 & 18.33 & 31.5 \\
4 & & 150 & 2.85 & 11.78 & 2.82 & 21.56 & 41.0 \\
1 & Direct (-) & 0 & 3.80 & 7.99 & 1.56 & 7.83 & 68.5 \\
6 & & 50 & 3.16 & 9.81 & 1.22 & 8.11 & 54.5 \\
5 & 150 & 3.57 & 9.80 & 2.01 & 11.17 & 55.0 \\
\hline
\end{tabular}

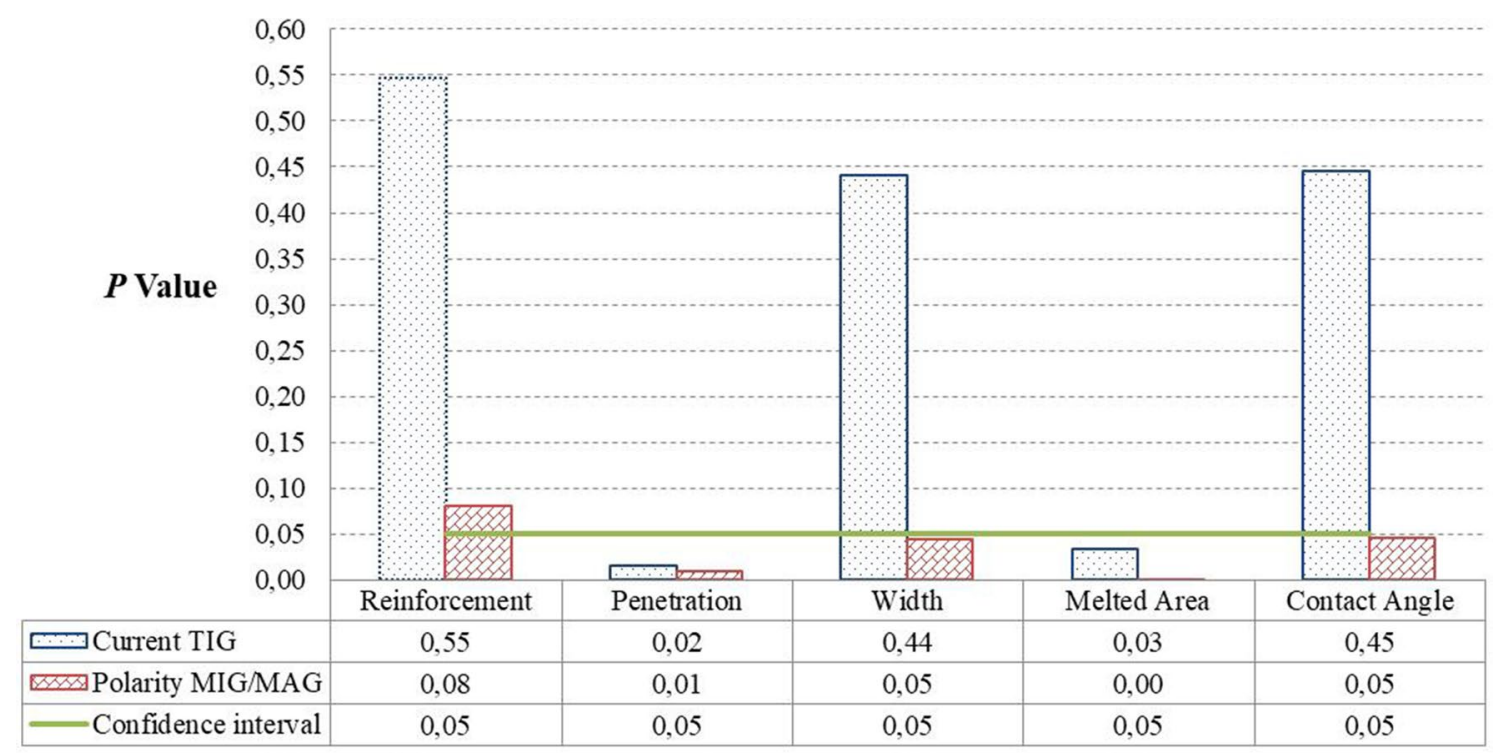

Fig. 2 Results of variance analysis

bead width for MIG/MAG welding torch in direct polarity. In the study of the Ref. [6], it was also noted that the intensity of TIG current showed no significance to the weld bead width. For inverse polarity current increment, it was noticed a weld bead of smaller width than that observed by the conventional process. A similar result was

\section{SN Applied Sciences}




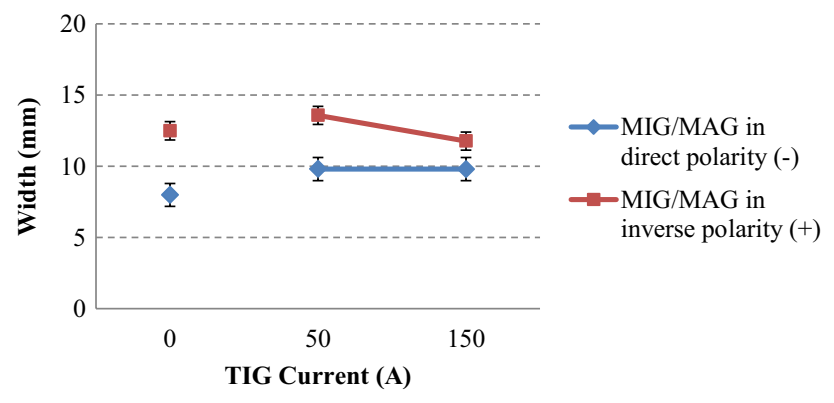

Fig. 3 Interaction effect of direct and inverse polarity on width

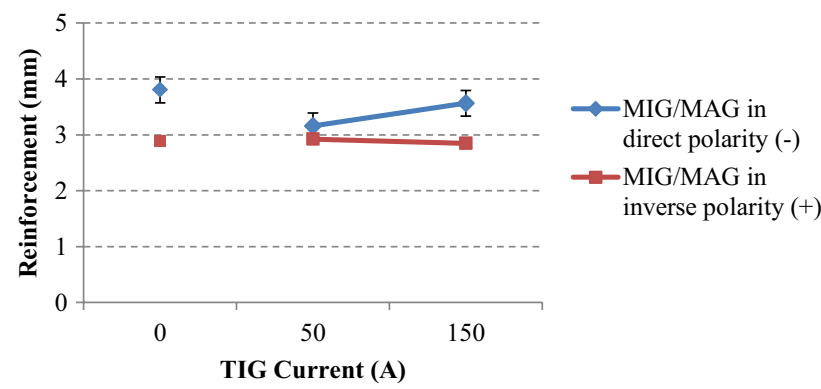

Fig. 4 Interaction effect of direct and inverse polarity on reinforcement

also noted in the Schneider [9], when best widths were obtained with intermediate levels of TIG current. Talkington [13] obtained in inverse polarity the largest weld bead widths for the MIG/MAG process.

Figure 4 shows the graph of interaction between variables to the reinforcement. The reinforcement according to the analysis of variance is only influenced by the variable polarity MIG/MAG. It is noted that the MIG/MAG in direct polarity has the weld bead reinforcement greater than the MIG/MAG in inverse polarity. This is the behavior identified in the literature with regard to the strengthening of the characteristics for each of the polarities.

The inclusion of TIG current in the process leads to a decrease in reinforcement. This decrease is due to the increased width of the strands. When one has wider weld beads then strengthening needs to decrease, a fact also noted by [16]. The increase in current TIG has very small variations related to reinforcement. The variable seems not to be significant in the analysis of variance as well as in the study of [6]. For the direct hybrid process, the lowest value is given with the current intensity of $50 \mathrm{~A}$. In the study of [9], the smallest reinforcements were also found in lower levels of TIG current.

Figure 5 shows data related to penetration. This output variable suffers significant influence of the two analyzed parameters. It is noticed that there is less penetration in

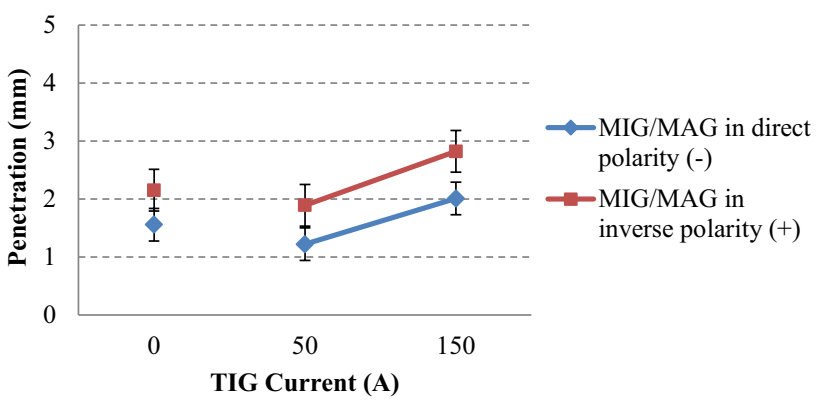

Fig. 5 Interaction effect of direct and inverse polarity on penetration

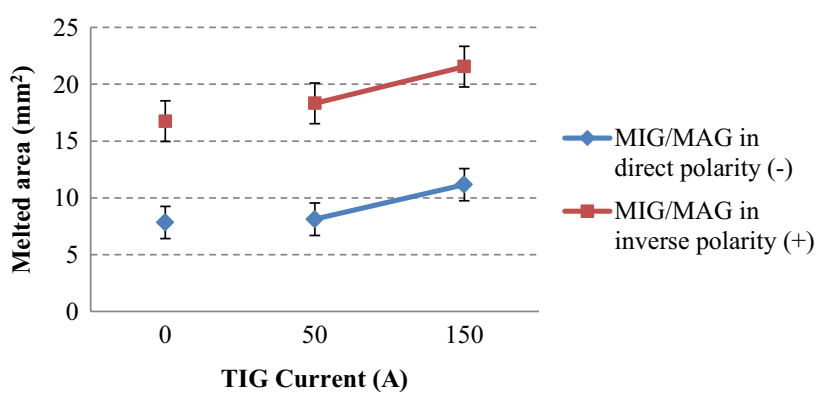

Fig. 6 Interaction effect of direct and inverse polarity on melted area

direct polarity, because in this configuration, the process requires a smaller amount of heat transferred to the part due to the characteristics of the processes. The insertion of the TIG arc with a current intensity of $50 \mathrm{~A}$ shows a lower penetration. This may have occurred due to the increase of the width of the strands. When a larger heated area energy transferred to the base metal is no longer concentrated, then a slightly reducing penetration takes place, as seen in [16]. The increase in the intensity of penetration TIG current of 150 A may be explained by Rodrigues [17]. He noticed that for the MIG/MAG process, in spray operating mode, higher current flows cause greater movement of the drops leading to an increased weld penetration. The study [18] shows that increasing the current TIG there is an increased penetration.

Figure 6 shows the dimensions of the molten area measured below the reference line of the plate, where one observes a tendency of increase of the molten area with the increase of the TIG current. It is also identified that the direct polarity produces strands with smaller melted area values.

Figure 7 shows the information related to the convexity angles. These angles determine the wettability of the weld. The literature shows that the smaller the angles, the greater the wettability. It can be seen that with the 


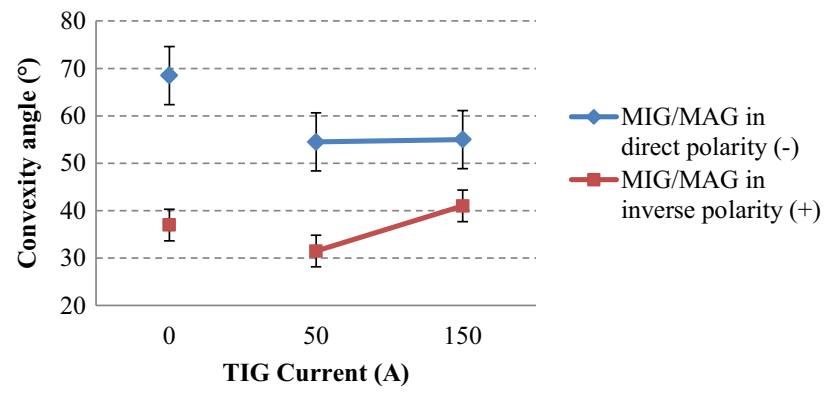

Fig. 7 Interaction effect of direct and inverse polarity on convexity angle

insertion of the TIG arc there is a tendency toward greater wettability. This increase already discussed above is now proven by the convexity angles.

\section{Conclusions}

One can achieve from these experiments in the evaluated parameters:

- Based on the $P$ value, the polarity of the MIG/MAG electrode had a significant effect on penetration, width, fused area, and wettability angle;

- In the TIG-MIG/MAG welding process, by varying the polarity of the MIG/MAG circuit and the intensity of the TIG current, it is possible to act on the geometry of the weld bead.

- The weld beads made with the MIG/MAG torch in direct polarity were more convex for higher levels of reinforcement and lower penetrations, while in inverse polarity the weld beads were wider with higher penetrations and lower reinforcements.

- The presence of the TIG arc was able to reduce the convexity of the weld beads, regardless of the polarity.

- The results indicate that it is possible to combine the highest fusion rate of the MIG/MAG process in direct polarity with the lowest convexity of the weld bead due to the effect of the TIG arc.

- For the levels and factors evaluated it was observed that the most influential factor in the results was the change in polarity of the MIG/MAG process.

\section{Compliance with ethical standards}

Conflict of interest The authors declare that they have no conflict of interest.

\section{References}

1. El Rayes M, Walz C, Sepold G (2004) The influence of various hybrid welding parameters on bead geometry. Weld $J$ 83(5):147S-153S

2. Messler RW Jr (2004) What's next for hybrid welding. Weld J 83(3):30-34

3. Kanemaru S, Sasaki T, Sato T, Era T, Tanaka M (2015) Study for the mechanism of TIG-MIG hybrid welding process. Weld World 59(2):261-268

4. Chen J, Zong R, Wu C, Padhy GK, Hu Q (2017) Influence of low current auxiliary TIG arc on high speed TIG-MIG hybrid welding. J Mater Process Technol 243:131-142

5. Meng X, Qin G, Zhang Y, Fu B, Zou Z (2014) High speed TIG-MAG hybrid arc welding of mild steel plate. J Mater Process Technol 214(11):2417-2424

6. Teixeira GS (2011) Análise da influência dos parâmetros de soldagem sobre a geometria do cordão de solda depositado pelo processo de soldagem TIG-MAG em tandem. Dissertation (Master's degree in Mechanical Engineering), Federal University of Rio Grande do Sul (UFRGS), Porto Alegre

7. Kanemaru S, Sasaki T, Sato T, Tanaka M (2012) Basic study on TIG-MIG hybrid welding process. Q J Jpn Weld Soc 30(1):29-34

8. Chen J, Wu CS, Chen MA (2014) Improvement of welding heat source models for TIG-MIG hybrid welding process. J Manuf Process 16(4):485-493

9. Schneider CF (2014) Otimização de um processo de soldagem híbrida TIG-MIG/MAG utilizando o método Taguchi. Course Completion Work (Mechanical Engineering), Faculty of Mechanical Engineering, Horizontina College, Horizontina

10. Zhang Y, Huang J, Cheng Z, Ye Z, Chi H, Peng L, Chen S (2016) Study on MIG-TIG double-sided arc welding-brazing of aluminum and stainless steel. Mater Lett 172:146-148

11. Zhang Y, Huang J, Ye Z, Cheng Z (2017) An investigation on butt joints of Ti6AI4V and 5A06 using MIG/TIG double-side arc welding-brazing. J Manuf Process 27:221-225

12. Lancaster JF (1986) The physics of welding, 2nd edn. Pergamom, New York

13. Talkington JE (1998) Variable polarity gas metal arc welding. Doctoral Thesis, The Ohio State University

14. Rontescu C, Cicic DT, lacobescu G, Amza GC (2015) The influence of the welding current polarity on the geometric configuration of the bead. Adv Mater Res 1088:797-801. https://doi. org/10.4028/www.scientific.net/AMR.1088.797

15. Souza $D$, Resende AA, Scotti A (2010) A qualitative model to explain the polarity influence on the fusion rate in the MIG/MAG process. Weld Int 24(12):934-941. https://doi.org/10.1080/09507 110903569032

16. Resende AA, Scotti A (2017) Influence of current levels, the tilt angle of the torch and the distance between the torch and the part on the geometry of the weld bead using 'Plasma-MIG' with concentric arcs. Weld Int 31(10):747-757. https://doi. org/10.1080/09507116.2016.1218628

17. Rodrigues CEAL (2007) Avaliação cinemática e dinâmica da transferência metálica na soldagem MIG/MAG. Doctoral Thesis, Federal University of Uberlândia, Uberlândia

18. Kanemaru S, Sasaki T, Sato T, Mishima H, Tashiro S, Tanaka M (2013) Study for TIG-MIG hybrid welding process: experimental consideration for optimum torch configuration. Q J Jpn Weld Soc 31(4):18s-21s

Publisher's Note Springer Nature remains neutral with regard to jurisdictional claims in published maps and institutional affiliations. 